\title{
Health Seeking Practices of Infertile Women
}

\author{
Chhabra S. ${ }^{*}$, Srujana D. and Annapurna M.A. \\ Obstetrics and Gynaecology, Mahatma Gandhi Institute of Medical Sciences, Sewagram, Wardha, Maharashtra, India
}

\begin{abstract}
Background: Infertility, reported commonly in gynecological practice, has many dimensions. There are many factors, visible / invisible and health seeking practices are also varied. Setting of Study: Department of Obstetrics and Gynaecology, Mahatma Gandhi Institute of Medical Sciences, Sevagram, Wardha, Maharashtra India. Objective: To find out knowledge of women about conception events, gross causes of infertility and the advice-seeking scenario of women with infertility. Subjects: Prospective study was done over two years. Material: One thousand (532 rural \& 468 urban) women were interviewed by social worker. Intervention: Analysis of information about duration of married life, problems in husband, wife and advice-seeking practices. Results: Women had little knowledge about conception events, possible treatment options for infertility, but were enthusiastic to know. Personnel from whom treatment was sought varied from quacks to specialist care-giver as entry place. Summary and Conclusion: Gross causes of infertility were tubal factors, anovulation, endocrine disorders and uterine causes. Infertile women from poor resource settings are not aware of possible causes of infertility. Some seek care from quacks, others visit specialist doctors as the first contact. Infertility therapy must encompass information, education and counseling also. Many women may need only awareness, counseling and no other medical/surgical interventions.
\end{abstract}

Keywords: Infertility, knowledge, causes, health-seeking behavior.

\section{INTRODUCTION}

Infertility, defined as the inability to conceive after one year of regular intercourse without contraceptive use, is said to affect $8-14 \%$ of couples [1-4]. It is a major reproductive health problem, at least in part, a cultural problem also. Women in particular, suffer from many social and medical consequences. After getting married some couples wait for years, others seek assistance within months. Many times it is only women, who seek advice, as there is family pressure. There is ignorance about whys \& hows of infertility. Advice seeking is not limited to regular health systems. Women go through various treatments seeking modes to avoid the adverse consequences of childlessness. They use varied traditional methods and religious practices, including visits to temple, abstaining from visiting a place where a woman has delivered a child, observing tantric rites, wearing charms, participating in rituals and visiting astrologers [5].

More recent studies have identified allopathy as the first treatment sought. Couples also follow religious practices with such treatment, either simultaneously or subsequently $[6,7]$. Either before or when allopathic treatment does not work, they seek other methods, such as ayurveda, homeopathy, unani and other traditional methods, or visit holy places and spiritual healers [6]. While assisted reproductive technology centers are the first ones to be visited by some, others seek assistance from religious people or quacks. But not much is known about these issues.

*Address correspondence to this author at the Obstetrics and Gynaecology, Mahatma Gandhi Institute of Medical Sciences, Sewagram, Wardha, Maharashtra, India; Tel: LL 07152- 284341-55, Ext. O-321, 307 R 221; M-09422141696; E-mail: chhabra_s@rediffmail.com

\section{Objectives}

To know about women's knowledge about conception, the gross causes of infertility and advice seeking practices of infertile women from poor resource settings.

\section{Material /Methods}

The study was conducted after taking informed consent at a rural institute over a period of 2 years to have a substantial number of cases, as a correct sample size was difficult to know. A total of 1000 infertile women from culturally diverse, urban and rural communities, attending outpatient care were the study subjects. Women who had reported with infertility, were interviewed with the help of a semi-structured questionnaire in the women's first language, about their awareness of conception events, gross causes of infertility and advice seeking practices; and the information collected was analysed.

\section{RESULTS}

Of 1000 women, $53 \%$ were rural and $47 \%$ urban. Of 532 rural, $48(9.02 \%)$ illiterate, $260(48.87 \%)$ educated and of 468 urban, $43(9.18 \%)$ illiterate and $270(57.69 \%)$ women educated up to various grades had consulted local doctors before coming to the tertiary care institute where the study was done, with no gross difference in rural and urban populations Out of 532 rural, 20(3.75\%)[one illiterate and 19 educated] and of 468 urban, 25(5.34\%) [4 illiterate and 21 educated] had already been to specialized infertility centers as the first choice, prior to the current visit (Fig. 1 and Fig. 2).

Out of 532 rural, only $15(2.8 \%)$ [7 illiterate and 8 educated] and of 468 urban also, 15(3.2\%)[6 illiterate and 9 educated] women had attended the study place as first place for 
Table 1. Health Seeking Behavior in Rural and Urban

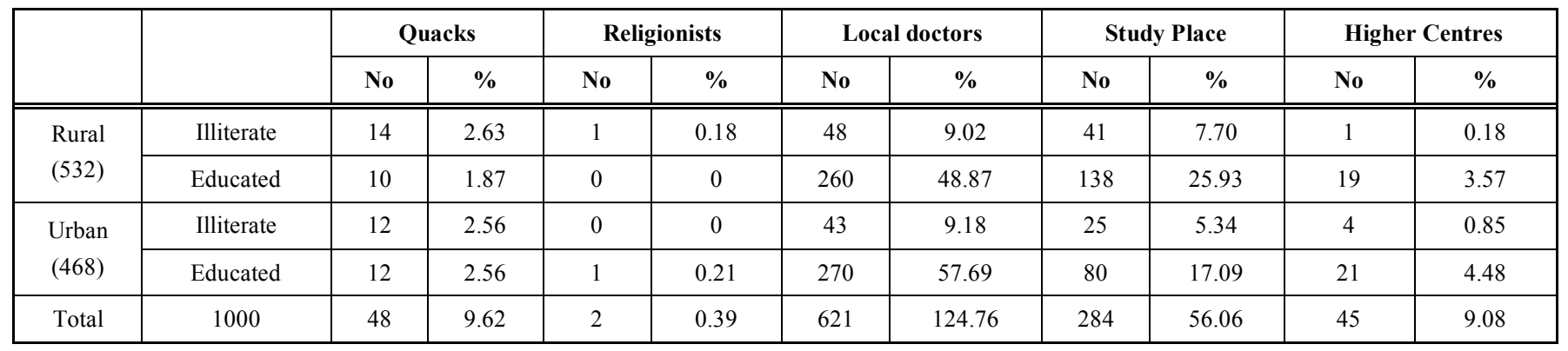

health seeking. Of 532 rural, 34(6.40\%) [5 illiterate and 29 educated] and of 468 urban, 15(3.20\%) [3 illiterate, and 12 educated] with married life $>10$ years had visited the institute where the study was done, as the first health facility (Fig. 2, Table 1).
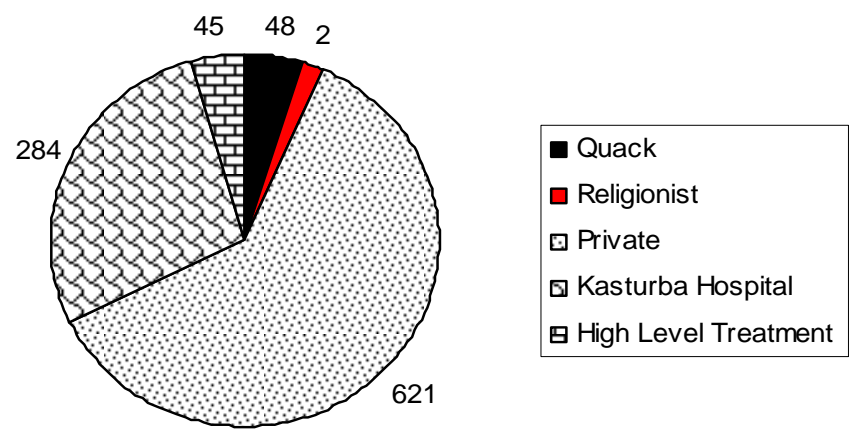

Fig. (1). Over all advice seeking.

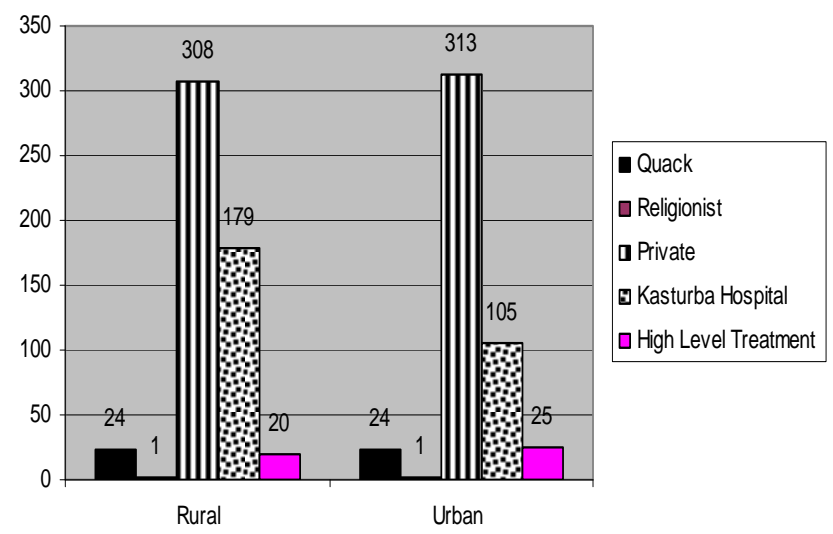

Fig. (2). Health seeking practices in rural urban.

\section{Obvious Causes of Infertility}

In $10.79 \%$ couples, male factor was the obvious cause; in $32.21 \%$ female factors, and in $20 \%$ couples, both male and female had obvious reasons responsible for infertility. In $37 \%$ cases, infertility appeared unexplained. Out of female factors, around $40 \%$ women had tubal factors, $30 \%$ had anovulation, endocrine disorders (thyroid disorders, hyperprolactinemia, polycystic ovarian disorders, luteal phase defect, diabetes etc.) were in $13 \%$, and uterine causes (hypoplasia, malformed uterus, tuberculous endometritis, fibroid uterus, synechiae etc.,) in $10 \%$ cases. There were other pelvic causes (pelvic inflammatory disease, endometriosis) and cervical mucous problems in $5 \%$ of the cases and $2 \%$ had coital problems. Male factors (10.79\%) included aspermia, azoospermia, oligospermia, teratospermia, erectile dysfuction, premature ejaculation, hypoactive sexual desire, etc. (Fig. 3).

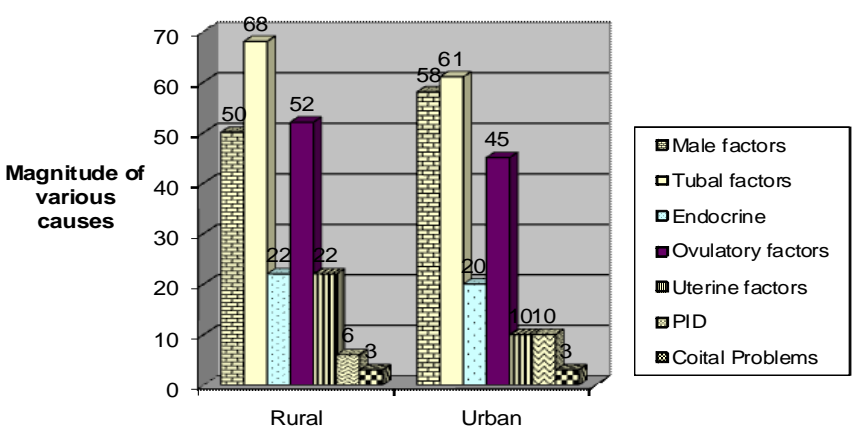

Demographic distribution

Fig. (3). Distribution of causes of infertility.

When asked about knowledge related to conception, $85 \%$ women said they knew that intercourse is required for conception; none could tell about the conception events and the knowledge about reproduction and treatment options for infertility was lacking. Similarly $138(13.80 \%)$ women had absolutely no information of possible causes of infertility; 799 women stated that they only knew that intercourse leads to conception, 51 women said that, they knew something was mixing in the woman's body, was 'working inside', 'causing a lot of changes' which subsequently grew into a baby. Amongst them, 35 women did use the word 'seeds', 'sperms' and 'eggs and sperms' 'mixing'. Compared to males, females (55\% females and 35\% males) were more conducive to health promotive practices.

\section{DISCUSSION}

Women take few months to years after marriage before seeking infertility advice. Our findings reveal several issues in infertility management strategies. A cardinal factor was the amount and quality of information available to patients. The present study is based on the analysis of information from 1000 women, around 53\% rural (532 couples) and 468 urban. Rural women were less than overall $65 \%$ rural health seekers at this rural institution. It may be due to ignorance or lack of awareness that less rural women report for health 
seeking for infertility. Analysis reveals that $16 \%$ women had absolutely no knowledge about the basic events of human reproduction.

Out of 532 rural women, overall $2.63 \%$ illiterate and $1.87 \%$ educated women had sought help from the local quacks as they were familiar with them, one $(0.18 \%)$ illiterate woman had consulted a religionist, $9.02 \%$ illiterate and $54.51 \%$ educated women had consulted local clinicians and $7.70 \%$ illiterate and $25.93 \%$ educated women had reported to the study place as first place and $0.18 \%$ illiterate women and $3.57 \%$ educated women had consulted specialized infertility centers before reporting to our center. Infertile couples seeking medical intervention often disregard lifestyle factors which could have adverse effects on fertility. So there is a need for education [8].

The present study revealed that 370 couples $(37 \%)$ were having unexplained infertility, a number much higher than currently reported $[9,10]$, may be because we are talking of gross factors responsible for infertility. Years back, Dodson et al. [11] had reported a figure of $30 \%$ unexplained infertility.

Neff in his study, the social construction of infertility, has reported the case of the matrilineal Nayars in south India. He says that the social responsibility and consequence are implicated and that these are traced matrilineally. It is the duty of matrilineal kin to attend to the family god of fertility and to the needs of females of the matrilineage to see that they foster progeny in the kin group's best interests [12].

More than a decade back Parikh et al. did a study on genital tuberculosis, a major pelvic factor causing infertility in Indian women and reported that out of the three hundred women, with tubal factors as a cause of their infertile state, one hundred were having tuberculosis as the cause of tubal blockage [13]. In a study by Chhabra et al. [14] in cases of infertility there were $12 \%$ cases of tubercular endometritis earlier and in recent past the number was only $1.2 \%$, indicating the decreasing trend of genital tuberculosis. Elussein et al. have reported unexplained infertility in $13 \%$ couples. Researchers have concluded that a tubal factor is the most common cause of infertility (nearly 30\%), followed by anovulation (22\%) [15].

Increasing information suggestive of a causal link between pesticide exposure and reproductive dysfunction in rural areas has been reported [16]. Pesticides may directly damage spermatozoa, alter Sertoli cell or Leydig cell function, or disrupt the endocrine function in any stage of hormonal regulation; however Clementi et al. [17] have challenged the hypothesis that living in rural areas, where large amounts of pesticides are applied, represents a risk factor for fertility. A study undertaken in Mozambique revealed that the explanations that infertile women could give for their childlessness originated more often from the traditional healers than from hospitals [18]. In another report from Gambia, women suffering from involuntary childlessness were largely unaware of the causes of infertility [19]. Common explanations included the concept of 'blocked tubes', 'weak sperm', abnormal menstrual periods and previously used family planning methods. Epidemiological studies indicate that cigarette smoking and alcohol consumption may modify fertility. Awareness of the adverse effects of smoking on fertility was more common among nonsmoker females. In men also, poor general health can affect fertility and smoking and alcohol consumption can impair spermatogenesis [20].

Education and information is essential in health care, and in infertility care it needs to take cognition of existing concepts as well as of women's concerns regarding the reasons of infertility. Lack of information is likely to cause or contribute to anxiety, which in itself can cause stress-related effects and also create a barrier to treatment. In the present study most of the women did not know much but expressed their desire for getting information. Roupa et al. did a study about the causes of infertility in Greece and reported that female infertility is a complex problem that should be considered carefully by the government and stakeholders in each country especially by those countries with demographic problems, in order to find effective interventions and solutions. In the same study it was also found that the most common cause of female infertility was problems in the fallopian tubes $(27.4 \%$ of the cases) and the second most common cause was the infertility of unknown cause, in $24.5 \%$ [21]. Data from African countries indicates that men and women attribute infertility to traditional beliefs about health and disease as well as to biomedical causes, although appropriate knowledge of the biomedical causes is frequently lacking [22]. The childless women have to suffer in various ways as a result of their health seeking behaviour. Despite their affiliation with modern treatment, urban childless women still believe, like their rural counterparts, that the remedy for chillessness ultimately depends on God. As a result, in addition to biomedical treatment many women return to or simultaneously pursue various traditional, spiritual or folk treatments [23]. Most of the help-seeking is undertaken by women, both traditional and modern biomedical health services, as was revealed in present study also. The provision of health education as an integral part of infertility management into reproductive health care programmes is needed. At the same time the importance of traditional health services in infertility management should be recognized as an important factor.

There is scarce information but research has highlighted a lack of fertility awareness especially in relation to the optimal fertile period during the menstrual cycle, incidence of infertility and duration of the reproductive life span [24]. Moreau et al. [25] have reported that the cumulative probability of medical consultation for involuntary infertility among nulligravid women was $45 \%$ after 12 months of involuntary infertility and $75 \%$ after 24 months. Highly educated women were more likely to have sought medical help for infertility.

The results of the present study indicate that awareness is likely to help women in accessing effective medical care, comply with treatment and deal with their childlessness. Unfortunately, either women do things because of ignorance or lack of counseling, or accessible systems for investigations or public health services commonly turn infertile women away from high technology modalities or some go to high technology centers without their need. The importance of health education and counseling is recognized, and both need to be integrated into infertility management. The introduction of clinical guidelines is recommended in order to 
overcome treatment barriers and improve the delivery of health services.

\section{CONFLICT OF INTEREST} article.

We do not have any conflict of interest with regard to this

\section{ACKNOWLEDGEMENTS}

We are grateful to the patients.

\section{REFERENCES}

[1] Emslie C, Grimshaw J, Templeton A. Do clinical guidelines improve general practice management and referral of infertile couples? BMJ 1993; 306(6894): 1728-31.

[2] Bhatti S, Rizvi JH, Zuberi NF, et al. Assisted reproductive technology: experience with IVF/ICSI. J Coll Physicians Surg Pak 2004; 14(5): 270-3

[3] Shefi S, Turek PJ. Definition and current evaluation of subfertile men. Int Braz J Urol 2006; 32: 385-97.

[4] Quaas A, Dokras A. Diagnosis and treatment of unexplained infertility. Rev Obstet Gynecol 2008; 1(2): 69-76.

[5] Desai P, Shrinivasan V, Hazra M. Eds. Understanding the emotions of infertile couples. J Obstet Gynaecol India 1992; 42: 498-503.

[6] Unisa S. Childlessness in Andhra Pradesh, India: treatment seeking and consequences. Reprod Health Matters 1999; 7: 54-64.

[7] Mulgaonkar VB. A research and an intervention programme on women's reproductive health in slums of Mumbai. Mumbai: Sujeevan Trust 2001.

[8] Olatunbosun OA, Edouard L, Pierson RA, How important is health promotion in the lifestyle of infertile couples? Clin Exp Obstet Gynecol 1997; 24(4): 183-6.

[9] Available at: www.medicinenet.com/script/main/art.asp?articlekey $=54432,2011$

[10] Available at: en.wikipedia.org/wiki/Infertility

[11] Dodson WC, Whitesides DB, Hughes CL, et al. Superovulation with intrauterine insemination in the treatment of infertility: a possible alternative to gamete intrafallopian transfer and in vitro fertilization. Fertil Steril 1987; 48: 441.
[12] Neff DL. The social construction of infertility: the case of the matrilineal Nayars in south India. Soc Sci Med 1994; 39(4): 47585.

[13] Parikh FR, Nadkarni SG, Kamat SA, Naik N, Soonawala SB, Parikh RM. Genital tuberculosis--a major pelvic factor causing infertility in Indian women. Fertil Steril 1997; 67(3): 497-500.

[14] Chhabra S, Tembhare A. Increasing trends of ovulatory dysfunction in infertile women with or without menstrual abnormalities. Indian Pract 2010; 63(12): 765-9.

[15] Elussein EA, Magid YM, Omer MM, Adam I. Clinical patterns and major causes of infertility among Sudanese couples. Trop Doct 2008; 38(4): 243-4.

[16] Bretveld R, Brouwers M, Ebisch I, Roeleveld N. Influence of pesticides on male fertility. Scand J Work Environ Health 2007; 33(1): 13-28.

[17] Clementi M, Tiboni GM, Causin R, et al. Pesticides and fertility: an epidemiological study in Northeast Italy and review of the literature. Reprod Toxicol 2008; 26(1): 13-8.

[18] Dyer SJ. The value of children in African countries - insights from studies on infertility. J Psychosom Obstet Gynecol 2007; 28(2): 6977.

[19] Dyer SJ, Abrahams N, Hoffman M, van der Spuy ZM. Infertility in South Africa: women's reproductive health knowledge and treatment-seeking behaviour for involuntary childlessness. Hum Reprod 2002b; 17: 1657-62.

[20] Pasqualotto FF, Lucon AM, Sobreiro BP, Pasqualotto EB, Sami Arap. The best infertility treatment for vasectomized men: assisted reproduction or vasectomy reversal? Rev Hosp Clin Fac Med Sao Paullo 2004; 59(5): 312-5.

[21] Roupa Z, Polikandrioti M, Sotiropoulou P, et al. Causes of infertility in women at reproductive age. Health Sci J 2009; 3(2): 80-7.

[22] Dyer SJ. Infertility-related reproductive health knowledge and help-seeking behaviour in African countries. ESHRE Monogr 2008; (1): 29-33

[23] Nahar P. Health seeking behaviour of childless women in Bangladesh: an ethnographic exploration. Soc Sci Med 2010; 71(10): 1780-7.

[24] Bunting L, Boivin J. Knowledge about infertility risk factors, fertility myths and illusory benefits of healthy habits in young people. Hum Reprod 2008; 23(8): 1858-64.

[25] Moreau C, Bouyer J, Ducot B, Spira A, Slama R. When do involuntarily infertile couples choose to seek medical help? Fertil Steril 2008; (2): 105-10.

(C) Chhabra et al.; Licensee Bentham Open.

This is an open access article licensed under the terms of the Creative Commons Attribution Non-Commercial License (http://creativecommons.org/licenses/by$\mathrm{nc} / 3.0 /$ ), which permits unrestricted, non-commercial use, distribution and reproduction in any medium, provided the work is properly cited. 